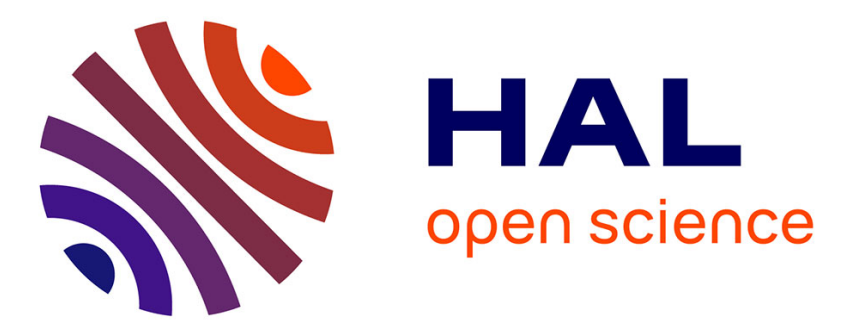

\title{
Rational design of tetrahydrogeraniol-based hydrophobically modified poly(acrylic acid) as emulsifier of terpene-in-water transparent nanoemulsions
}

\author{
L.-I. Atanase, C. Larraya, J.-F. Tranchant, M. Save
}

\section{- To cite this version:}

L.-I. Atanase, C. Larraya, J.-F. Tranchant, M. Save. Rational design of tetrahydrogeraniol-based hydrophobically modified poly(acrylic acid) as emulsifier of terpene-in-water transparent nanoemulsions. European Polymer Journal, 2017, 94, pp.248-258. 10.1016/j.eurpolymj.2017.07.011 . hal-01689453

\section{HAL Id: hal-01689453 https://hal.science/hal-01689453}

Submitted on 2 Dec 2020

HAL is a multi-disciplinary open access archive for the deposit and dissemination of scientific research documents, whether they are published or not. The documents may come from teaching and research institutions in France or abroad, or from public or private research centers.
L'archive ouverte pluridisciplinaire HAL, est destinée au dépôt et à la diffusion de documents scientifiques de niveau recherche, publiés ou non, émanant des établissements d'enseignement et de recherche français ou étrangers, des laboratoires publics ou privés. 


\section{Rational design of tetrahydrogeraniol-based hydrophobically modified poly(acrylic acid) as emulsifier of terpene-in-water transparent nanoemulsions}

Leonard-Ionut Atanase, ${ }^{*, a, d}$ Carlos Larraya, ${ }^{\mathrm{b}}$ Jean-François Tranchant, ${ }^{\mathrm{c}}$ Maud Save*,a

${ }^{a}$ CNRS / Univ Pau \& Pays Adour, Institut des sciences analytiques et de physico-chimie pour l'environnement et les matériaux-UMR 5254, Equipe de Physique et Chimie des Polymères,, 64000, Pau, France

${ }^{b}$ Aquitaine Science Transfert, 351 cours de la Libération, 33405, Talence-cedex, France

${ }^{c}$ LVMH Recherche Parfums et Cosmétiques, 185 Av. de Verdun, St Jean de Braye, F-45804,

France

${ }^{d}$ Present address: University Apollonia, Faculty of Dental Medicine, 3 str. Muzicii, Iasi, Romania

*Corresponding authors: maud.save@univ-pau.fr, leonard.atanase@yahoo.com

\section{ABSTRACT}

Amphiphilic copolymers based on renewable resources were involved as emulsifiers to prepare transparent terpene-in-water nanoemulsions. The amphiphilic copolymers are composed of hydrophobically modified poly(acrylic acid) (HMPAA) grafted with different fractions of hydrophobic bio-based tetrahydrogeraniol (THG) side chains. The well-defined PAA were synthesized by reversible addition fragmentation transfer (RAFT) polymerization in order to tune the number-average molar mass of the initial PAA. The self-assembly in aqueous solution of the HMPAA copolymers was investigated through the measurement of their critical aggregation concentration by viscometry, tensiometry, dynamic light scattering and the determination of their aggregation number by static light scattering. Series of oil-in-water nanoemulsions using dihydromyrcenol (DHM) terpene as dispersed phase and PAA-THG as emulsifier were prepared with different PAA-THG/DHM weight ratios and DHM/water weight ratios. The level of transparency of the emulsions was monitored though the transmittance value measured at $600 \mathrm{~nm}$ and the measurements of the hydrodynamic diameter of droplets by dynamic light scattering. This study highlights that the structure of the PAAx-THGy is a key parameter to prepare terpene-inwater nanoemulsions with the required high level of transparency. The optimised structure of the emulsifier consists in a moderate degree of polymerization of PAA backbone $\left(\overline{D P_{n}}, \mathrm{PAA} \leq 180\right)$ 
along with an intermediate average degree of substitution in hydrophobic THG side chains $(13 \leq$ $\overline{D S} \leq 32)$.

Keywords: amphiphilic copolymers; RAFT polymerization; Terpenes; renewable resources; nanoemulsion;

\section{Introduction}

Microemulsions were defined as a system of water, oil and surfactant (also named stabilizer or emulsifier) which is a single optically isotropic and thermodynamically stable system with dispersed domain size varying approximately from 10 to $100 \mathrm{~nm}$, usually 10 to $50 \mathrm{~nm}$.[1, 2] In a microemulsion, the domains of the dispersed phase in the phase diagram are either globular (waterin-oil (W/O) or oil-in-water $(\mathrm{O} / \mathrm{W})$ droplets) or interconnected to provide a bicontinuous structure. A microemulsion mostly involves a quaternary system composed of water, oil, surfactant and a hydrophobe miscible in water like $n$-butanol[3] or acetone[4] for instance. In the present work, we will focus our attention on $\mathrm{O} / \mathrm{W}$ emulsion with droplet structure prepared by applying ultrasonication shear in the absence of additional hydrophobic solvent apart from the oil. The term nanoemulsion is also used for O/W emulsions with droplet size in the order of $100 \mathrm{~nm}$.[5-8] By contrast to the thermodynamically stable microemulsion independent of the preparation process (simple mixing), nanoemulsion is associated to kinetically stable emulsions formulated with a lower amount of surfactant to produce process dependent droplets prepared for instance by external shear.[5] In summary, microemulsion and nanoemulsions have similarities in the final size of droplets but nanoemulsion are kinetically stable emulsions with small droplet sizes (range 20 $100 \mathrm{~nm}$ ) regardless the method of preparation.[6-8] Therefore, the term nanoemulsion will be preferred in the present work.

The range of nanoemulsion applications includes drug delivery systems, food industry, and cosmetic industry.[8-10] Contrary to macroemulsions (often called shortly as an 'emulsion' with droplet size of hundreds of micrometers), no inherent creaming, sedimentation, flocculation, or coalescence is observed for nanoemulsions.[11] Another difference concerns their appearance as emulsions are cloudy while nanoemulsions are transparent or translucent. This property is especially relevant for the cosmetic industry to develop alcohol-free transparent formulation of fragrances. In specific applications of cosmetics, different challenges should be simultaneously addressed: preparation of transparent alcohol-free fragrance formulations, use of efficient 
emulsifier with minimum toxicity and meeting the increasing demand for reducing the dependence on fossil resources by increasing the use of renewable resources. In cosmetics, nanoemulsions are preferred to microemulsion to minimize the toxicological risk of skin irritation induced by a high level of surfactant.

The present work aims to address these challenges by synthesizing amphiphilic copolymers from renewable resources as macromolecular emulsifiers of terpene-based transparent nanoemulsions. Such macromolecular emulsifiers improve the emulsion stability with respect to the conventional molecular surfactants due to much slower desorption kinetics at the interface of the droplet.[12] Moreover, macromolecular emulsifiers of molar mass above 5 to $10 \mathrm{kDa}$ reduce skin toxicity by limiting diffusion across skin barrier. According to Osipow et al. [13], a transparent nanoemulsion is favored by matching the stabilizer and the oil phase chemical structure. In addition, the transparent nanoemulsions are characterized by droplet sizes in the range of 20 to $100 \mathrm{~nm}$ and by high storage stability against Ostwald ripening. As terpenes are a major component of fragrance formulations, the covalent attachment of hydrophobic terpenes onto a hydrophilic polymer backbone to prepare amphiphilic copolymers is a strategy to match the structure of the dispersed phase while simultaneously integrating renewable resources in the copolymer emulsifier. Amphiphilic copolymers provide attractive surface and interfacial properties resulting from the incompatibility between the chemically different sequences linked together in the same macromolecule. $[14,15]$ The platform terpene molecules $(\alpha$ - and $\beta$-pinene) are produced from pine woods via distillation of either turpentine or paper oil, a by-product of the paper-making industry. The range of synthesized terpenes, which are branched or cyclic C10 and C15 molecules, represent an alternative to oil seeds and palm oil. It is worth to mention that acrylic acid monomer used to synthesize poly(acrylic acid) (PAA) can be produced from renewable resources, ie from 3 hydroxypropionic acid produced from glucose.[16, 17] PAA is among the most common pHresponsive polymer with a pKa of 4.5.[18, 19] The level of protonation of the carboxylic groups switches the net hydrophilic-hydrophobic character of the polymer. At $\mathrm{pH}$ values above 4.5, the PAA is neutralized to form the water soluble anionic poly(sodium acrylate) (PANa). On the contrary, at $\mathrm{pH}<4.5$ precipitation occurs in aqueous solutions due to protonation of the carboxylate groups, which renders the polymer only sparsely soluble in water.[20] Hydrophobically modified poly(acrylic acid) (HMPAA) have proved to be an interesting class of amphiphilic copolymers with a wide range of properties. HMPAA are extensively used as 
stabilizers and rheology modifiers in paints, cosmetics, pharmaceuticals, foods, enhanced oil recovery, water treatment and controlled release of bioactive materials. [21-23] The hydrophobic interactions, and thus the solution properties, can be controlled by either the type or the grafting density of hydrophobic groups.[24, 25] or by addition of salts and surfactants. [26, 27] HMPAA have demonstrated stabilizing properties for the preparation of gold nanoparticles [28] or for direct oil-in-water emulsions.[14, 29-32] Lockhead et al.[32] highlighted that hydrophobically-modified PAA were more efficient stabilizers than non-modified PAA for cyclohexane/water and mineral oil/water emulsions in a semi-dilute regime. Perrin et al.[14, 30] studied the emulsifying properties of a series of HMPAA for n-dodecane/water macroemulsions and concluded to a stronger anchoring of polymers to oil droplets and hence a better stabilization for a substitution degree $(\overline{D S})$ higher than $10 \mathrm{~mol} \%$ or a longer alkyl chains. PAA samples of molar mass ranging between 5 and $5000 \mathrm{~kg} \cdot \mathrm{mol}^{-1}$ were hydrophobically modified with aliphatic aromatic or fluorocarbon groups by peptidic coupling or by copolymerization. [14, 24, 30-33] Up to now, mostly fossil-based resources were involved in the hydrophobic modification of PAA while there is a global need in reducing the dependence on petrochemical resources.[34-36] In the variety of biomass feedstock, terpenes have known a growing interest in recent studies of polymer chemistry.[37-41]

The originality of the present work is to prepare amphiphilic copolymers based on tetrahydrogeraniol (THG) terpene and well-defined poly(acrylic acid) in order to stabilize solventfree transparent nanoemulsion of dihydromyrcenol (DHM) in water. In addition to mimicking the structure of the stabilizer side groups with the one of the dispersed oil phase, the use of tetrahydrogeraniol increases the biomass content. At this point it is worth mentioning that the preparation of terpene-in-water nanoemulsions, using exclusively D-limonene as oil phase, was studied until now only in the presence of commercially available stabilizers, generally based on ethylene oxide units[42-44], and mixed surfactants of low molecular weights.[45] The major drawback of these surfactants is related not only to their polydispersity in composition and in molar mass but also to their possible irritating effect on skin which makes them undesirable in cosmetic formulations. Moreover, it was stated by Schellekens et al. [46] that the oligo(ethylene oxide) sequences of these products may be immunogenic and that the anti-OEO antibodies induce blood clearance and reduce efficacy of the products. 
In order to thoroughly investigate the relationship between the macromolecular features of the HMPAA stabilizers, their solution properties and the nanoemulsion features, the present work proposes to control the molar mass and dispersity of the PAA backbone together with the substitution degree of the HPMAA amphiphilic stabilizers.

\section{Experimental}

2.1. Materials. The following materials were purchased from Sigma Aldrich and used as received: 4-cyano-4-[(dodecylsulfanylthiocarbonyl)sulfanyl] pentanoic acid (97\%), acrylic acid (AA, 99\%), 4,4'-azobis(4-cyanovaleric acid) (ACVA, 98\%), N,N'-dicyclohexylcarbodiimide (DCC, 99\%), 4(dimethylamino)pyridine (DMAP, 95\%) and anhydrous ethanol. The terpenes used in this study were supplied by Dérivés Résiniques Terpéniques (DRT Company) and the structures of the THG and DHM are reported in Supporting Information (Figure S1). Anhydrous dimethylsulfoxide (DMSO, Technical grade, VWR) was obtained by using molecular sieves that were previously dried under vacuum at $100^{\circ} \mathrm{C}$. A sodium citrate buffer solution at $\mathrm{pH} 6$ (Roth) was used as continuous phase for viscosimetry, surface tension and light scattering measurements as well as continuous phase for emulsions.

2.2. Synthesis of poly(acrylic acid) (PAA) by RAFT polymerization. As a typical example for the synthesis of PAA90 (Table 1), a solution of AA (12.5 g, 0.1736 mol), 4-cyano-4[(dodecylsulfanylthiocarbonyl)sulfanyl] pentanoic acid $\left(0.4843 \mathrm{~g}, 1.736 \times 10^{-3} \mathrm{~mol}\right)$, and ACVA $\left(0.0486 \mathrm{~g}, 1.74 \times 10^{-4} \mathrm{~mol}\right)$ in absolute ethanol $(37.5 \mathrm{~g})$ was degassed with $\mathrm{N}_{2}$ for $120 \mathrm{~min}$. RAFT polymerization of AA was carried out at $80^{\circ} \mathrm{C}$, and samples were withdrawn every 30 min under nitrogen flow. After $180 \mathrm{~min}$, the reaction was stopped by cooling followed by exposing the mixture to air. The monomer conversion was calculated by on the basis of the signals corresponding to the vinylic protons of AA monomer at $6.2 \mathrm{ppm}$ and to the aliphatic protons of the methine of PAA backbone at $2.2 \mathrm{ppm}$. The product was purified by precipitation into cold diethyl ether. This operation was repeated 3 times by dissolving PAA in ethanol prior subsequent precipitation. The polymer was lyophilised to recover a white powder.

\subsection{Synthesis of hydrophobically modified PAA (HMPAA) by esterification of PAA with THG}

In a typical experiment, $1 \mathrm{~g}\left(4.72 \times 10^{-5} \mathrm{~mol}\right)$ of PAA294 was dissolved in $5 \mathrm{ml}$ of anhydrous DMSO. Then, $0.1493 \mathrm{~g}\left(9.45 \times 10^{-4} \mathrm{~mol}\right)$ of THG was added and the temperature was set at $60^{\circ} \mathrm{C}$. 
At this temperature, $12 \mathrm{mg}\left(9.84 \times 10^{-5} \mathrm{~mol}\right)$ of 4-(dimethylamino)pyridine (DMAP) and 0.1946 $\mathrm{g}\left(9.45 \times 10^{-4} \mathrm{~mol}\right)$ of $N-N^{\prime}$ dicyclohexylcarbodiimide (DCC) (dissolved in $1 \mathrm{~g}$ of DMSO) were added dropwise into the flask under vigorous stirring. The temperature was maintained at $60^{\circ} \mathrm{C}$ and the reaction mixture was stirred for $20 \mathrm{~h}$. The system is then cooled down to room temperature and $5 \mathrm{ml}$ of ethanol are added. The dicyclohexylurea crystals are eliminated by filtration and the polymer was precipitated into cold diethyl ether and solubilised into ethanol. This operation was repeated 3 times and then crude product is dissolved in water and finally freeze-dried to obtain a white powder.

2.4. Preparation of aqueous solutions of HMPAA and of terpene-in-water emulsions. The PAATHG copolymers were directly mixed with sodium citrate buffer solution at pH 6 at the desired concentration, the solutions were stirred overnight at room temperature and filtered through PVDF $0.45 \mathrm{~mm}$ filters. Polymer concentrations ranged between 1 to $5 \mathrm{wt} \%$ corresponding to 10 to $50 \mathrm{~g} . \mathrm{L}^{-}$ 1. The emulsions were prepared by adding the DHM oil phase to the copolymer solutions in sodium citrate buffer and stirred for 5 minutes prior to be emulsified at high shear pressure using a VibraCell 72408 ultrasonicator for $2 \mathrm{~min}$ at amplitude of $30 \%$. Emulsion containers were immersed into an ice bath during sonication process and the distance of the tip from the bottom of the tube was the same for all experiments. The total mass of the emulsions was kept equal to $10 \mathrm{~g}$ and the weight fractions of DHM versus continuous phase ranged between 0.2 and $2 \mathrm{wt} \%$.

Methods. ${ }^{1} \mathrm{H},{ }^{13} \mathrm{C}$, and DOSY (diffusion-ordered spectroscopy) nuclear magnetic resonance (NMR) spectra were recorded at $25^{\circ} \mathrm{C}$ on a Brüker $400 \mathrm{MHz}$ spectrometer in DMSO-d 6 .

The number average molar mass $\left(\overline{M_{n}}\right)$ and dispersity $\left(\bigoplus=\overline{M_{w}} \overline{M_{n}} /\right)$ of the methylated PAA $(=$ poly(methyl acrylate), PMA) were analyzed by size exclusion chromatography (SEC) running at $30^{\circ} \mathrm{C}$ with THF as eluent at a flow rate of $1 \mathrm{~mL} \cdot \mathrm{min}^{-1}$. The SEC system was equipped with three Waters Styragel columns HR 0.5, 2, 4 working in series (separation range $1 \times 10^{2}$ to $3 \times 10^{6}$ g.mol ${ }^{-}$ ${ }^{1}$ ), a refractive index detector ERC 7515-A and a MALLS WYATT Optilab detector operating at $633 \mathrm{~nm}$. All polymer samples were prepared at 1 to 5 g.L $\mathrm{L}^{-1}(0.1$ to $0.5 \mathrm{wt}-\%)$ concentrations and filtered through PVDF $0.45 \mathrm{~mm}$ filters. The $\overline{M_{n}}$ of the PMA samples was determined from SEC MALLS using a value of $d n / d c$ value measured at $0.060 \mathrm{~mL} \cdot \mathrm{g}^{-1}$ which is close to the one reported in reference [47].

The theoretical value of $\overline{M_{n}}$ was calculated according to $\overline{M_{n}}=\frac{[\mathrm{AA}]_{0} \cdot \mathrm{M}_{\mathrm{AA}} \cdot \text { conversion }}{[\mathrm{CTA}]_{0}+[\mathrm{ACVA}]_{0}\left(1-\mathrm{e}^{-\mathrm{kd}}\right)}+M_{\mathrm{CTA}}$ 
With $M_{\mathrm{AA}}$ and $M_{\mathrm{CTA}}$ the molecular weight of acrylic acid and of the trithiocarbonate chain transfer agent respectively, $k_{\mathrm{d}}$ the dissociation rate constant of ACVA in water at $80^{\circ} \mathrm{C}\left(k_{\mathrm{d}}=9 \times 10^{-5}\right.$ from reference [48].

The derivatized HMPAA samples were analyzed by proton NMR in order to calculate the average number of THG group grafted per polymer chain $\left(N_{\mathrm{THG} / \mathrm{PAA}}\right.$, Erreur ! Source du renvoi introuvable.) and the average degree of substitution $(\overline{D S})$ corresponding to a molar percent versus AA monomer units (Erreur ! Source du renvoi introuvable.).

$N_{\mathrm{THG} / \mathrm{PAA}}=\left(I_{\mathrm{a}} / 9\right) /\left(I_{\mathrm{b}} / \overline{D P_{n}}, \mathrm{NMR}\right)$

\section{Equation 1}

$\overline{D S}=\left(100 \times \mathrm{N}_{\mathrm{THG} / \mathrm{PAA}}\right) / \overline{D P_{n}}, \mathrm{NMR}$

\section{Equation 2}

Dynamic viscosities were determined with a rolling-ball AMVn Anton Parr micro-viscometer at $20^{\circ} \mathrm{C}$ and the results provided in the present work are the average of 5 measurements. The specific viscosity was calculated as follows: $\eta_{\mathrm{sp}}=\left(\eta-\eta_{0}\right) / \eta_{0}$, where $\eta_{0}$ is the dynamic viscosity of the buffer solution at $\mathrm{pH} 6$ and $\eta$ is the dynamic viscosity of the copolymer solution at a given concentration.

Dynamic light scattering (DLS) measurements of the micellar sizes and emulsion droplets size were performed with a Vasco-2 Particle Size Analyzer from Cordouan Technologies working at an angle of $135^{\circ}$ and a wavelength of $658 \mathrm{~nm}$. Autocorrelation functions were recorded using a multi-acquisition mode and the apparent diffusion coefficients were determined via the PadeLaplace inverse algorithm. The hydrodynamic diameter was calculated from the Stokes-Einstein equation based on the diffusion coefficient. Both size distributions in intensity and in volume are provided in this work in order to gain a better insight into the droplets sizes characterization. The size distribution is derived from the intensity autocorrelation functions fitted with either single or multiple relaxation time distribution. The volume distribution traduces the volume fractions of particles of a given radius.

Static light scattering (SLS) measurements, of HMPAA solutions with concentrations ranging from 10 to 50 g.L $\mathrm{L}^{-1}$ ( 1 to $5 \mathrm{wt}-\%$ ), were performed with a particle size analyser from Cordouan Technologies at different angles, between 30 and $140^{\circ}$. The root mean square radius, also called 
the radius of gyration $R_{\mathrm{g}}$, was determined by using the Zimm equation: $\frac{K c}{R(\theta, c)}=\frac{1}{M_{w}}(1+$ $\left.\frac{q^{2} R_{g}^{2}}{3}\right)\left(1+2 M_{w} A_{2} c\right)$, where $\overline{M_{w}}$ is the average weight molar mass, $K=4 \pi^{2} n_{0}^{2}\left(\frac{d n}{d c}\right)^{2} / N_{A} \lambda^{4}$ and $R(\theta)=R_{T}\left[\left(I-I_{\text {sol }}\right) / I_{\text {tol }}\right]$ the Rayleigh ratio of solution, $R_{T}$ is the Rayleigh ratio of toluene and is equal to $1.35 \times 10^{-5} \mathrm{~cm}^{-1}$ for a HeNe laser, $I, I_{t o l}$ and $I_{s o l}$ are the intensity of light scattered at $\theta$ angle by respectively the polymer solution, toluene and solvent, $n_{0}$ the refractive index of the solvent, $n_{T}$ the refractive index of the toluene, $N_{\mathrm{A}}$ Avogadro's number. The refractive index increment $d n / d c$ characterizes the change of the refractive index $n$ with the concentration $c$. The $d n / d c$ value of the HMPAA in water at $\mathrm{pH} 6$ was considered equal to 0.15.[49] The scattering

vector is $q=4 \pi n_{0} \sin \left(\frac{\theta}{2}\right) / \lambda$ with $\lambda$ the wavelength of the light source, $c$ is the concentration of polymer in solution.

The measurements of interfacial tension (IFT) and surface tension of the copolymer solutions were studied from dynamic measurements carried out using a Tracker tensiometer from TECLIS (Longessaigne, France), at $20.0 \pm 0.2^{\circ} \mathrm{C}$. An oil drop was formed by using a needle, with a diameter of $0.84 \mathrm{~mm}$, was immersed in PAA-THG aqueous solution for IFT measurements while a drop a PAA-THG aqueous solution was formed in air for surface tension measurements. The shape of the drop was followed on a CDD camera and surface tension was deduced from the mathematical analysis of this axial symmetrical shape (Laplacian profile). The drop volume was kept constant by automatic adjustment. Time $\mathrm{t}=0$ was measured immediately after bubble formation.

UV-Visible spectroscopy was performed with a Shimadzu UV-2450PC spectrophotometer in the 500 to $800 \mathrm{~nm}$ range, using a quartz cell with a path length of $1 \mathrm{~cm}$.

\section{Results and discussion}

\subsection{Synthesis of poly(acrylic acid)(PAA) by RAFT polymerization and preparation of HMPAA.}

Among the controlled radical polymerization techniques, reversible addition fragmentation polymerization (RAFT) involving a chain transfer agent (CTA)[50] and nitroxide mediated free radical polymerization (NMP)[51] proved their efficiency in controlling the polymerization of acrylic acid (AA) monomer. For such monomer, RAFT polymerization allows to perform the polymerization at lower temperature, hence broadening the range of available solvents, while NMP 
was mainly performed at $110^{\circ} \mathrm{C}$ in dioxane. In the present work, the polymerization of acrylic acid (AA) was mediated by the 4-cyano-4-[(dodecylsulfanylthiocarbonyl)sulfanyl] pentanoic acid CTA and carried out in ethanol at $80^{\circ} \mathrm{C}$ in the presence of $4,4^{\prime}$-azobis(4-cyanovaleric acid) as initiator (see Step 1 in Scheme 1).

Step 1:
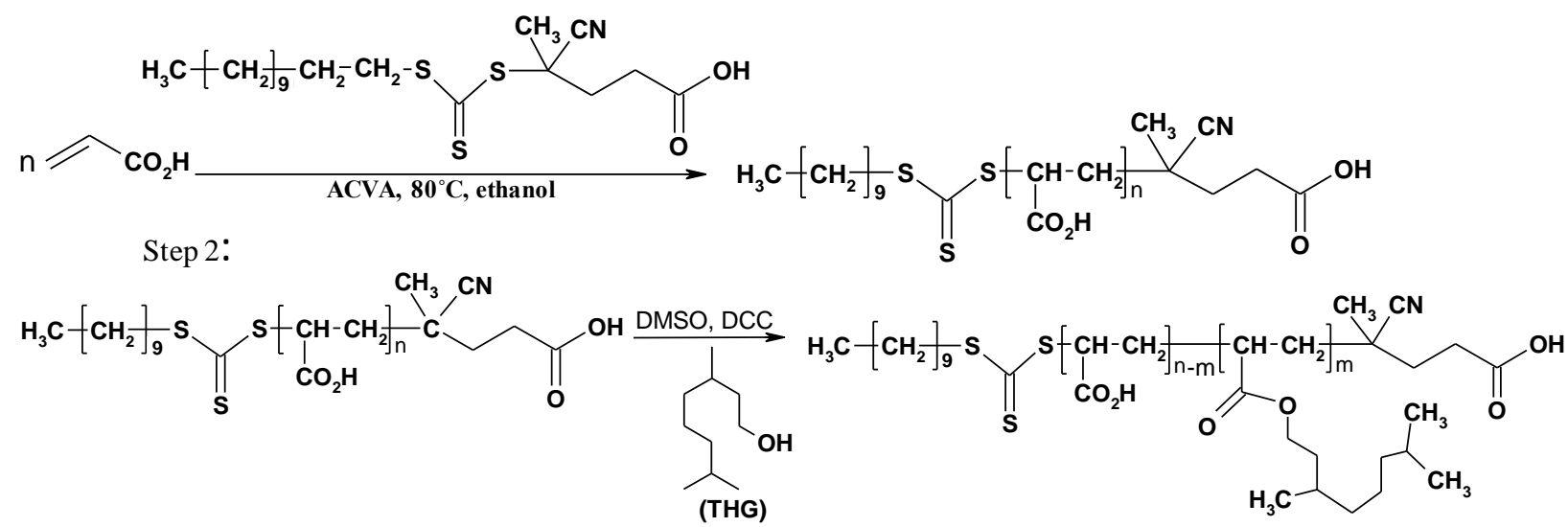

Scheme 1. Step 1: RAFT polymerization of AA mediated by 4-cyano [(dodecylsulfanylthiocarbonyl)sulfanyl] pentanoic acid as chain transfer agent (CTA); Step 2: Synthesis of THG hydrophobically modified PAA.

A series of poly(acrylic acid) was prepared by varying the initial [AA]/[CTA] ratio at constant monomer concentration of 2.9 M. The macromolecular features of PAA reported in Table 1 show that polymers with different values of $\overline{M_{n}}$ can be synthesized by tuning the initial concentration of the trithiocarbonate chain transfer agent. The SEC chromatograms of final PAA are unimodal and symmetrical with dispersity ranging between 1.2 and 1.4 (Figure S3 in ESI and Table 1), indicating polymers with a rather homogeneous distribution of chain lengths. As expected from literature, 4cyano [(dodecylsulfanylthiocarbonyl)sulfanyl] pentanoic acid is an efficient chain transfer agent to control acrylic acid polymerization by the RAFT process.

Table 1. Macromolecular features of the PAA series synthesized by RAFT polymerization in ethanol at $80{ }^{\circ} \mathrm{C}$ for 3 hours of polymerization, $[\mathrm{AA}]_{0}=2.9 \mathrm{~mol} \mathrm{~L}^{-1}$. 


\begin{tabular}{|c|c|c|c|c|c|c|c|}
\hline Sample & $\frac{[\mathbf{A A}]_{0}}{[\mathbf{C T A}]_{0}}$ & Conv. & $\begin{array}{c}\overline{D P_{n}}, \text { PAA, } \\
\mathrm{NMR}^{a}\end{array}$ & $\begin{array}{c}\overline{M_{n}}, \text { PMA, SEC }{ }^{b} \\
\left(\mathrm{~g} \mathrm{~mol}^{-1}\right)^{\mathrm{b}}\end{array}$ & $\boldsymbol{\oplus}^{b}$ & $\overline{D P_{n}}$, PAA, SEC $c$ & $\frac{\overline{D P_{\mathrm{n}, \mathrm{NMR}}}}{\overline{D P_{\mathrm{n}, \mathrm{SEC}}}}$ \\
\hline PAA90 & 100 & 0.90 & 90 & 11310 & 1.21 & 127 & 0.71 \\
\hline PAA180 & 200 & 0.90 & 180 & 17280 & 1.24 & 196 & 0.92 \\
\hline PAA294 & 300 & 0.98 & 294 & 20770 & 1.35 & 236 & 0.80 \\
\hline PAA345 & 400 & 0.86 & 345 & 24450 & 1.46 & 280 & 0.80 \\
\hline
\end{tabular}

${ }^{a}$ The number average degree of polymerization $\left(\overline{D P_{n}}\right.$, PAA, NMR $)$ of PAA was calculated as follows: $\overline{D P_{n}}$, PAA, NMR $=I_{\mathrm{b}} /\left(I_{\mathrm{a}} / 3\right)$; where $I_{\mathrm{a}}$ and $I_{\mathrm{b}}$ are the integral values of respectively the methyl group of PAA chain end from the trithiocarbonate $\mathrm{CTA}\left(\delta_{\mathrm{CH} 3}=0.8 \mathrm{ppm}\right)$ and the methine group of the PAA backbone $\left(\delta_{\mathrm{CH}}=2.2 \mathrm{ppm}\right)$ in the proton NMR spectra. A typical example of ${ }^{1} \mathrm{H}$ NMR spectrum is given in ESI (Figure S2).

${ }^{b}$ Number-average molar mass and dispersity of methylated PAA determined by SEC-MALLS;

${ }^{c} \overline{D P_{n}}$,PAA,SEC values were calculated as follows: $\overline{D P_{n}}$, PAA, SEC $=\left(\overline{M_{n}}\right.$, PMA, SEC, MALLS $\left.-M_{\mathrm{CTA}}\right) / 86$, as the molar mass of the methyl acrylate monomer unit corresponding to the methylated PAA is 86 g.mol ${ }^{-1}$.

The average degree of polymerization calculated from the proton NMR spectra $\left(\overline{D P_{n}}\right.$, NMR $)$ evolves according to the initial $[\mathrm{AA}]_{0} /[\mathrm{CTA}]_{0}$ ratio and shows comparable values within the range of $10 \%$ error limits with the theoretical degree of polymerization $\left(\overline{D P_{n}}=\right.$ monomer conversion $\times$ $[\mathrm{AA}]_{0} /[\mathrm{CTA}]_{0}$ ) (see Table 1). It should be noticed that the values of $\overline{D P_{n}}$, SEC calculated on the basis of the number-average molar mass of the methylated PAA measured by SEC (MALLS detector) are systematically higher than those determined by NMR (Table 1). The values of the $\overline{D P_{n}}$, NMR $\overline{D P_{n}}$, SEC ratio ranging between 0.7 and 0.9 indicate that $\overline{D P_{n}}$, NMR is underestimated due to the partial functionalization of PAA chains by the dodecyl trithiocarbonate end group as $\overline{D P_{n}}$, NMR is calculated considering $100 \%$ of dodecyl chain ends. The partial functionalization of PAA is the sign of irreversible chain transfer reactions to ethanol solvent. The decrease of the slope of

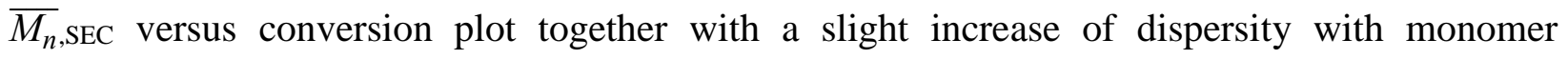
conversion (see Figure S4 in ESI) also support the occurrence of irreversible transfer reactions to ethanol, as reported by Loiseau et al..[50] It has been previously shown that replacing ethanol by 1,4-dioxane reduces such side reactions, [50,52] though ethanol was preferred in this study to reduce solvent toxicity for cosmetic applications. Despite these transfer reactions, the macromolecular features of the poly(acrylic acid) synthesized in the present work were controlled 
by the initial ratio of monomer over chain transfer agent to provide a series of PAA with a range of $\overline{M_{n}}$ and a narrow molar mass distribution.

The PAA samples of different molar masses were hydrophobically modified by grafting the tetrahydrogeraniol (THG) monohydroxy-terpene via a Steglich esterification reaction involving DMAP and DCC as catalysts (step 2 in Figure 1). The NMR spectra of PAA-THG and THG are displayed in Figure S4, which highlights the absence of overlap between the methine signals of PAA backbone at $2.2 \mathrm{ppm}$ and the tetrahydrogeraniol signals.

Table 2 summarizes the features of the series of HMPAA synthesized by esterification reactions with different initial fractions of THG versus acrylic acid units of PAA. In the following, these copolymers will be designated as PAAx-THGy with $x$ for $\overline{D P_{n}}$, NMR and $y$ for THG molar content.

Table 2: Features of HMPAA series synthesized by Steglich esterification with $\mathrm{THG}$ at $60^{\circ} \mathrm{C}$ for $20 \mathrm{~h}$.

\begin{tabular}{c|c|c|c|c|c} 
PAA & Samples & $\boldsymbol{r}_{\mathbf{0}}(\boldsymbol{\%})^{\boldsymbol{a}}$ & $\boldsymbol{N T H G / P A A}^{b}$ & $\begin{array}{c}\overline{\mathbf{D S}} \boldsymbol{c} \\
(\boldsymbol{\%})\end{array}$ & $\begin{array}{c}\text { Efficiency }^{\boldsymbol{d}} \\
(\boldsymbol{\%})\end{array}$ \\
\hline \multirow{3}{*}{ PAA90 } & & & 12 & 13 & 59 \\
\cline { 2 - 6 } & PAA90-THG13 & 22 & 35 & 39 & 89 \\
\cline { 2 - 6 } & PAA90-THG51 & 55 & 46 & 51 & 93 \\
\hline \multirow{3}{*}{ PAA180 } & PAA180-THG7 & 11 & 12 & 7 & 64 \\
\cline { 2 - 7 } & PAA180-THG13 & 22 & 23 & 13 & 59 \\
\cline { 2 - 7 } & PAA180-THG32 & 33 & 56 & 32 & 96 \\
\cline { 2 - 7 } & PAA180-THG45 & 44 & 80 & 45 & 100 \\
\hline \multirow{2}{*}{ PAA294 } & PAA294-THG7 & 12 & 20 & 7 & 59 \\
\cline { 2 - 7 } & PAA294-THG13 & 20 & 39 & 13 & 65 \\
\hline \multirow{2}{*}{ PAA345 } & PAA345-THG5 & 13 & 18 & 5 & 38 \\
\cline { 2 - 7 } & PAA345-THG13 & 17 & 44 & 13 & 76 \\
\hline
\end{tabular}


${ }^{a} r_{0}=100 \times n_{\mathrm{THG}, 0} / n_{\mathrm{AA}, 0}$ with $n_{\mathrm{AA}, 0}$ the number of moles of acrylic acid units in PAA, $n_{\mathrm{AA}, 0}=$ $m_{\mathrm{AA}, 0} / M_{\mathrm{AA}}$.

${ }^{b}$ Number of THG per PAA chains calculated with Erreur ! Source du renvoi introuvable..

${ }^{c}$ Degree of substitution calculated with Erreur ! Source du renvoi introuvable..

${ }^{d}$ Esterification efficiency $=\overline{D S} / r_{0}$.

The results of Table 2 show that the degree of substitution $(\overline{D S})$ of PAA-THG can be tuned by the initial ratio of THG versus AA $\left(r_{0}\right)$ with an increase of the esterification efficiency from 38 to 100 $\%$ by rising $r_{0}$.

In order to confirm the efficient grafting of the THG, the purified copolymer was analysed by DOSY NMR (Figure 1). On the basis of the alignment of the diffusion coefficients of the methyl signal of THG moiety at $\delta=0.8 \mathrm{ppm}$ and the PAA backbone $(\delta=1.0-2.3 \mathrm{ppm})$, one can conclude to an efficient THG grafting and the absence of free THG with lower diffusion coefficient.

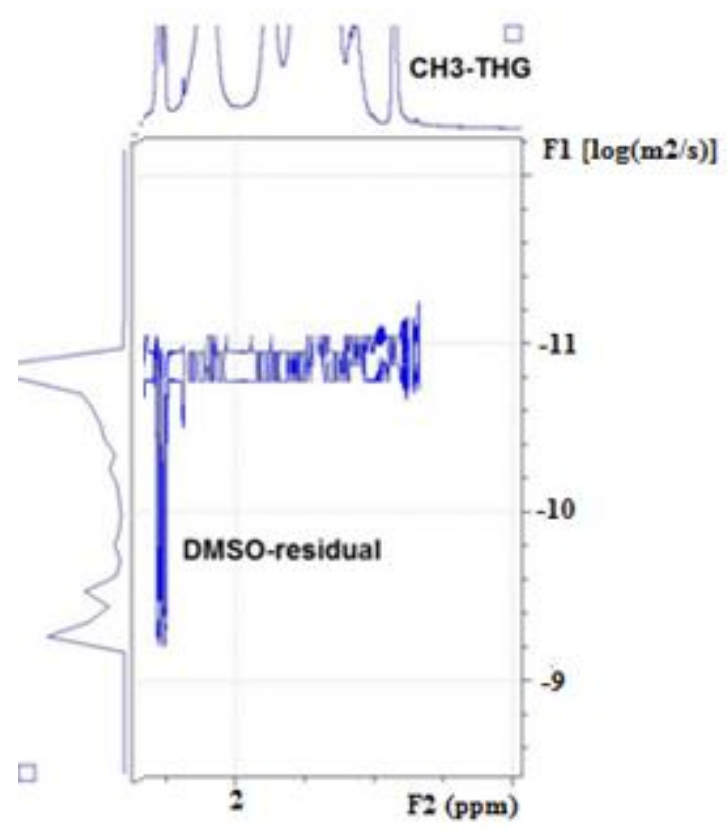

Figure 1. DOSY NMR spectrum of PAA90-THG39 copolymer in DMSO-d 6 .

\subsection{Characterization of the PAA-THG aqueous solutions}


With the aim to prepare transparent direct $\mathrm{O} / \mathrm{W}$ nanoemulsions stabilized by the amphiphilic PAATHG, the transmittance at wavelength of $600 \mathrm{~nm}$ of the HMPAA aqueous solution at $\mathrm{pH} 6$ as well as the hydrodynamic diameters of the copolymers in solution were measured (see Table S1 in ESI). Aqueous solutions of $1 \mathrm{wt} \%$ of PAA-THG produced transparent solutions with a value of transmittance above $98 \%$ for the entire series of copolymers except for PAA180-THG45 with the highest degree of substitution (Table S1, $\mathrm{T}_{\lambda}=600 \mathrm{~nm}=62 \%$ ). At this point it has to be mentioned that the samples PAA90-THG39 and PAA90-THG51 samples are not completely soluble in the sodium citrate buffer solution at $\mathrm{pH}$. The lower transmittance of the aqueous solution of the more hydrophobic PAA180-THG45 copolymer is due to the presence of larger aggregates of mean hydrodynamic diameter $\left(D_{\mathrm{h}}\right)$ centered at $190 \mathrm{~nm}$ while the analysis of the aqueous solutions of the other PAA-THG copolymers highlights that the main $D_{\mathrm{h}}$ of copolymer assemblies is systematically below $15 \mathrm{~nm}$ (Table S1). Dynamic light scattering reveals the presence of larger aggregates $\left(D_{\mathrm{h}}>\right.$ $200 \mathrm{~nm}$ ) for all the copolymer solutions but represented as a minor population as the volume distribution shows only one population $D_{\mathrm{h}}$ in the $8-13 \mathrm{~nm}$ range (Table $\mathbf{S 1}$ and Figure S6).

It was of interest to determine the critical aggregation concentration (CAC) of the HMPAA in order to evaluate the self-assembly of the copolymer at the concentrations used to prepare the oilin-water nanoemulsions. The values of CAC of the HMPAA were monitored by three different methods based on light scattering, viscosimetry and tensiometry. In order to assess the impact of the length of the PAA backbone on the CAC, we selected four HMPAA samples with a similar degree of substitution $(\overline{D S}=13 \mathrm{~mol} \%)$ and varied $\overline{M_{n}}$ of PAA. The intensity of the scattered light of the aqueous PAA-THG copolymer solutions, measured via the average counts rate at constant laser intensity, was plotted as a function of the copolymer concentration (Figure 2). The crossover of the slopes indicates CAC values of PAAx-THG13 ranging between 3.0 and 4.5 g.L $\mathrm{L}^{-1}$ (0.30 to $0.45 \mathrm{wt}-\%$ ) (Figure 2). It has been previously demonstrated that slope break of scattered light intensity is as sensitive as fluorescence spectroscopy for the determination of the CAC.[53, 54] 


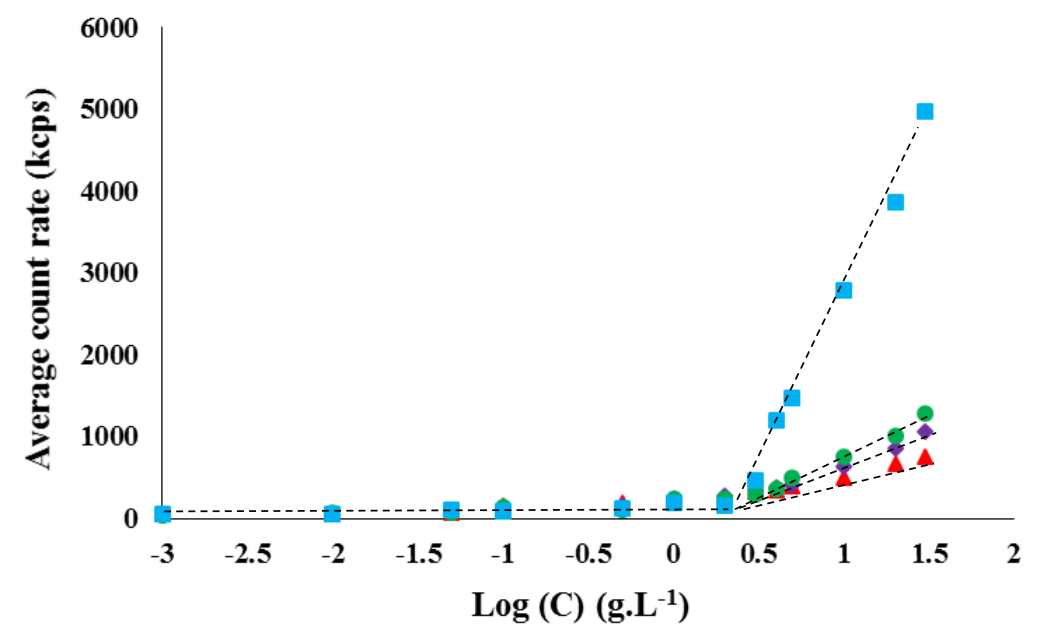

Figure 2. Intensity of the scattered light versus logarithmic concentration of HMPAA for PAA90THG13 (triangles), PAA180-THG13 (diamonds), PAA294-THG13 (circles) and PAA345-THG13 (squares) in buffer solution at $\mathrm{pH} 6$ at $20^{\circ} \mathrm{C}$.

The evolution of the specific viscosity of the PAAx-THG13 aqueous solutions by rising the copolymer concentration follows a similar trend with values of $\mathrm{CAC}$ at crossover point in a similar range of 3.0 to $4.5 \mathrm{~g} . \mathrm{L}^{-1}$ ( 0.30 to $0.45 \mathrm{wt}-\%$ ) (Figure 3 ). Note that the reduced viscosity expectedly increases with increasing the degree of polymerization of PAA (see slopes of Figure 3).

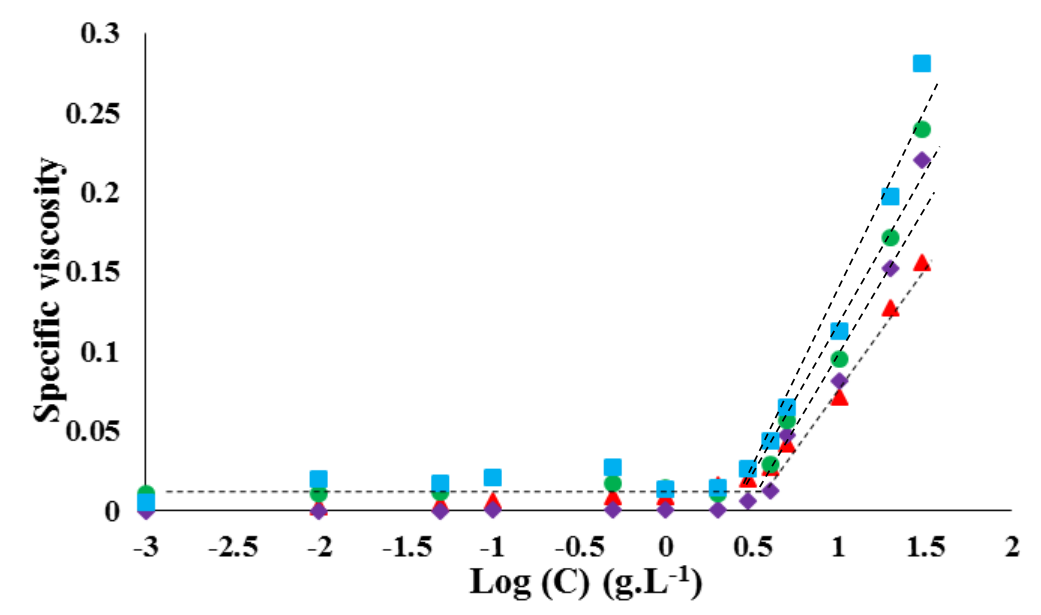

Figure 3. Specific viscosity versus copolymer concentration at $20^{\circ} \mathrm{C}$ for PAA90-THG13 (triangles), PAA180-THG13 (diamonds), PAA294-THG13 (circles) and PAA345-THG13 (squares) 
Finally, the decrease of the surface tension $(\gamma)$ as a function of the copolymer concentration also provides $\mathrm{CAC}$ values at the first crossover point, with values of $\mathrm{CAC}$ also ranging between 3.5 to

$$
\left.4.5 \text { g.L } \mathrm{L}^{-1} \text { (0.30 to } 0.45 \mathrm{wt}-\%\right) \text { ( }
$$

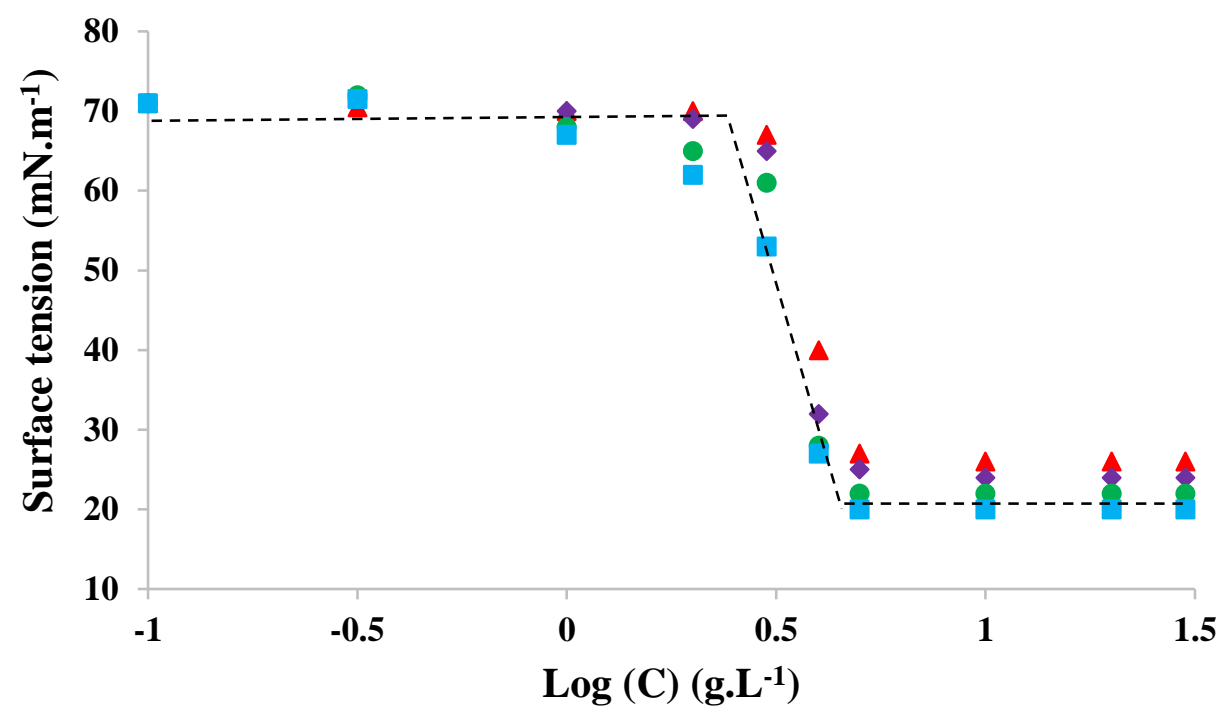

Figure 4).

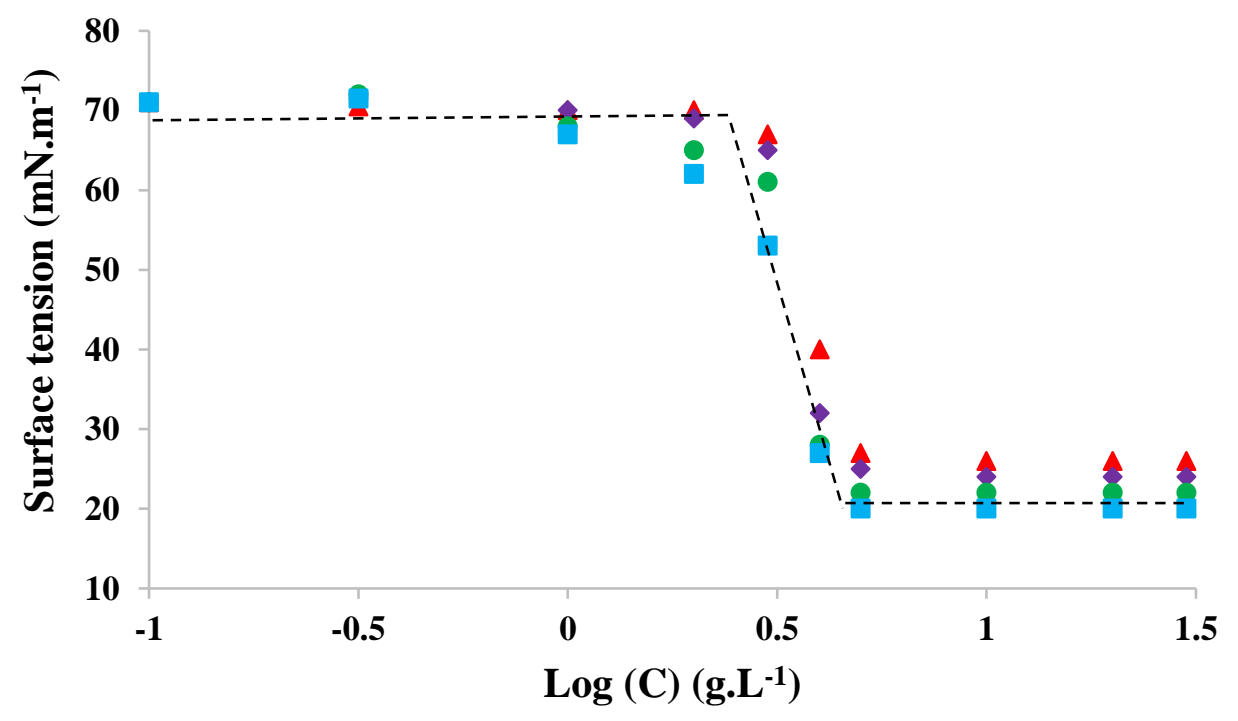


Figure 4. Surface tension versus copolymer concentration at $20^{\circ} \mathrm{C}$ for PAA90-THG13 (triangles), PAA180-THG13 (full diamonds), PAA294-THG13 (circles) and PAA345-THG13 (squares).

The values of the critical aggregation concentration of the series of PAAx-THG13 measured by DLS, viscometry and tensiometry are summarized in Table 3. It can be concluded that the average CAC value decreases by increasing $\overline{M_{n}}$ of PAA backbone at constant $\overline{D S}$ of 13 mol\%. For a constant $\overline{D P_{n}}$,NMR $($ PAA180), rising the fraction of hydrophobic grafted THG from 13 to 32 mol$\%$ (Table 3, PAA180-THG13 and PAA180-THG32) induces a decrease of the CAC value.

Table 3. Values of critical aggregation concentration (CAC) of PAA-THG copolymer in aqueous solution.

\begin{tabular}{c|c|c|c|c}
\multirow{2}{*}{\begin{tabular}{c}
\multirow{2}{*}{ Sample } \\
\cline { 2 - 4 }
\end{tabular}} & \multicolumn{3}{|c|}{ CAC (g.L-1) } & Average CAC value \\
\cline { 2 - 4 } & DLS & Viscometry & Tensiometry & $4.2 \pm 0.2$ \\
\hline PAA90-THG13 & 4.5 & 4.0 & 4.0 & $4.2 \pm 0.2$ \\
\hline PAA180-THG13 & 4.0 & 4.0 & 4.5 & $3.7 \pm 0.2$ \\
\hline PAA294-THG13 & 3.5 & 3.5 & 4.0 & $3.2 \pm 0.2$ \\
\hline PAA345-THG13 & 3.0 & 3.0 & 3.5 & $3.8 \pm 0.2$ \\
\hline PAA180-THG32 & 3.5 & 4.0 & 4.0 & \\
\end{tabular}

It should be mentioned that the concentrations of PAAx-THGy in water further used for the preparation of the direct o/w nanoemulsions range between 10 and $50 \mathrm{~g} . \mathrm{L}_{\mathrm{H} 20}{ }^{-1}$ (1 to $5 \mathrm{wt} \%$ ) which is 3 to 10 times higher than the CAC values (Table 3). In order to characterize the self-assembled aggregates of the HMPAA copolymer in water, we attempted to determine the aggregation number $\left(N_{\text {agg }}\right)$ of the PAAx-THGy (Table S2). The aggregation number is the ratio between $\overline{M_{W}}$ of the selfassembled PAA-THG in water calculated from the Zimm plot and $\overline{M_{W}}$ of the HMPAA single 
copolymer measured by SEC THG (calculated on the basis of $\overline{M_{W}} \overline{M_{n}}$,SEC and $\overline{D S}$ reported in Table 2). The copolymers with a degree of substitution below 15 mol- $\%$ tend to self-assemble into dimers $\left(N_{\mathrm{agg}} \sim 1.5-2.5\right)$ except for PAA with the highest PAA chain length (PAA345-THG13, $\left.N_{\mathrm{agg}} \sim 14\right)$ which aggregates into more diffusing objects (see Figure 2). The increase of the grafted hydrophobic tetrahydrogeraniol fraction up to $32 \mathrm{~mol}-\%$ for PAA180 induces an increase of the aggregation number to trimers (Table S2). These results are in concordance with those obtained by Hao et al.[55] who investigated the self-assembly of dodecyl-modified PAA copolymers in water for PAA of $\overline{M_{W}}=2.5 \times 10^{5} \mathrm{~g} \cdot \mathrm{mol}^{-1}$. These copolymers self-assembled into either unimolecular chains for a dodecyl content in the range of 10 to $34 \mathrm{wt}-\%$, or to plurimolecular aggregates of four chains for a dodecyl content up to $40 \mathrm{wt}-\%$.

\subsection{Characterization of the terpene-in-water direct emulsions}

Dihydromyrcenol (DHM) was used as dispersed oil phase for the preparation of different oil-inwater emulsions. The concentration of the amphiphilic PAA-THG copolymer used as stabilizer was varied between 10 to 50 g.L. $\mathrm{L}^{-1}(1$ and $5 \mathrm{wt}-\%)$ versus the water phase. The fraction of the DHM dispersed phase ranged between 0.2 and 2 wt- $\%$ based on the total volume of the emulsion. As described in the experimental section, the emulsions were prepared by the following procedure: the PAA-THG amphiphilic copolymer at the required concentration is first poured into the aqueous buffer solution at $\mathrm{pH} 6$ prior to add the dihydromyrcenol oil phase. The emulsion is submitted to stirring and ultrasonication high shear.

We first monitored the impact of the amphiphilic PAA-THG copolymer on the DHM/water interfacial tension (IFT), which plays an important role in the emulsification process. It is well known that the interfacial tension is affected by the surfactant concentration and molar mass and also by its hydrophilic/lipophilic balance. It should first be mentioned that all PAA-based copolymers are efficient stabilizers as the presence of these copolymer systematically induced a decrease of the interfacial tension in comparison with the initial value of DHM/aqueous buffer solution system showing an IFT value of $9.8 \mathrm{mN} / \mathrm{m}$ at $600 \mathrm{~s}$. The impact on the IFT of the degree of polymerization $\left(\overline{D P_{n}}\right)$ of the initial PAA backbone was investigated for the copolymer series exhibiting a degree of substitution in THG equal to 13 mol-\% (PAA $x$-THG13 with $x=\overline{D P_{n}}$, NMR $=$ 180, 294, 345, see Figure S7 in ESI). The perfect overlay of the plots reveals the absence of 
significant effect of $\overline{D P_{n}}$ of PAA backbone of the HMPAA on the IFT values. On the other hand, the degree of substitution of PAA180-THGy $(x=\overline{D S}=0,7,13,32$ see Figure S8 in ESI) noticeably influences the interfacial tension. Indeed, IFT values decreased by increasing the substitution degree from 0 to $32 \mathrm{~mol} \%$ of hydrophobic THG. As expected, the lowest value of IFT, of $2 \mathrm{mN} / \mathrm{m}$, was obtained for PAA180-THG32 copolymer with the highest fraction of grafted hydrophobic THG. The effect of $\overline{D P_{n}}$ and $\overline{D S}$ of PAA-THG amphiphilic copolymers on interfacial tension between dihydromyrcenol and water is summarized in Figure 5.

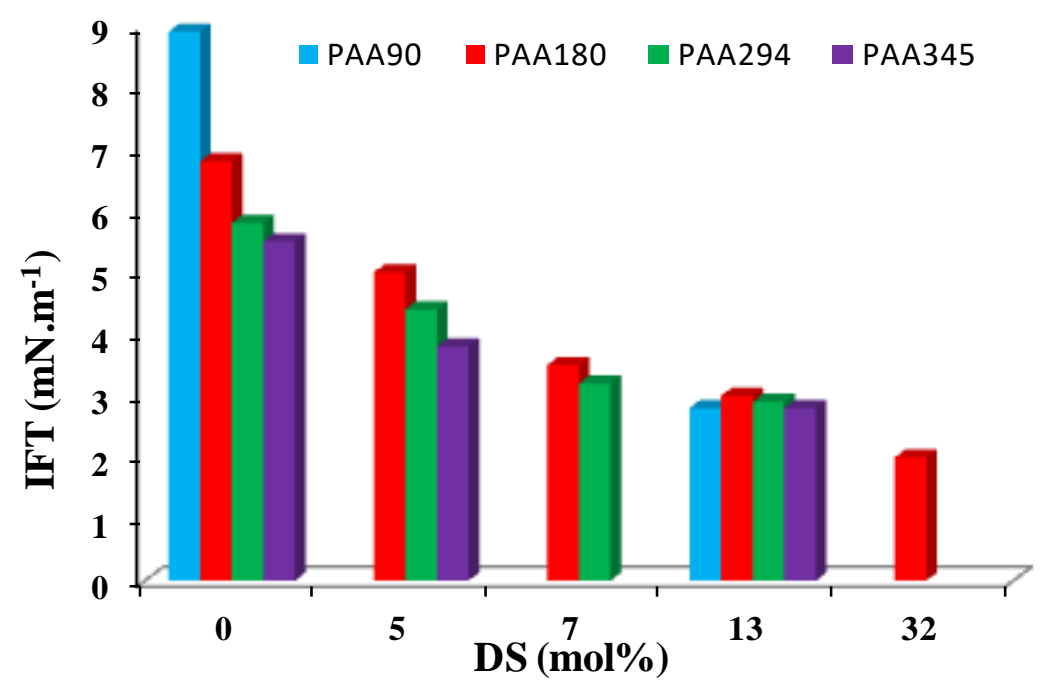

Figure 5. Variation of the interfacial tension (IFT) of DHM/water as a function of the degree of substitution $(\overline{D S})$ for PAA $x$-THG $D S$ with $\overline{D P_{n}}$,PAA $=x=90,180,294,345$. The copolymer concentration is 10 g. $\mathrm{L}^{-1}(1 \mathrm{wt} \%)$ based on the aqueous solution at $\mathrm{pH} 6$ (sodium citrate buffer), $\mathrm{T}$ $=20^{\circ} \mathrm{C}$. The reference IFT value of DHM/water in the absence of polymer is $9.8 \mathrm{mN} \cdot \mathrm{m}^{-1}$

Figure 5 evidences that the most significant effect on the DHM/water interfacial tension is the degree of substitution as increased $\overline{D S}$ reduced IFT value for all PAA-THG copolymers. The decrease of IFT by rising the $\overline{D P_{n}}$ of PAA backbone is observed for PAA $(\overline{D S}=0)$ and PAA-THG of low $\overline{D S}(<7 \mathrm{~mol} \%)$ but this effect is minimized for $\overline{D S}$ of $13 \mathrm{~mol} \%$.

A first series of terpene in water direct emulsion stabilized by the terpene-based HMPAA copolymer was prepared with $0.2 \mathrm{wt} \%$ of dihydromyrcenol (DHM) and $10 \mathrm{~g} \cdot \mathrm{L}^{-1}(1 \mathrm{wt} \%)$ of PAATHG based on the water phase at $\mathrm{pH} 6$ (Table 4). The variation of the emulsion transparency, assessed through the transmittance at wavelength at $600 \mathrm{~nm}$, as a function of both the average degree of polymerization of the PAA backbone and the $\overline{D S}$ value, is summarized in Table 4 . It 
should be mentioned that the emulsions of the present work were classified in the following three categories, according to the transmittance $(T)$ values at $600 \mathrm{~nm}$ as well as visual observations (see pictures in Figure 6): transparent emulsions with $T$ ranging between $70 \%$ and $100 \%$, transluscent emulsions for $T$ values ranging between $50 \%$ and $70 \%$ and cloudy emulsions characterized by a transmittance lower than $50 \%$.

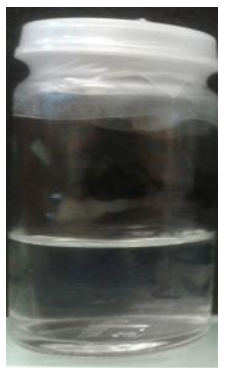

Transparent $\mathrm{T}=70-100 \%$

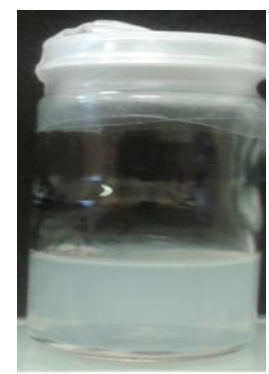

Translucent $\mathrm{T}=50-70 \%$

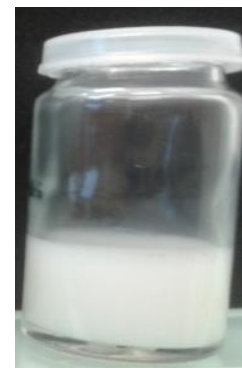

Cloudy $\mathrm{T}=0-50 \%$

Figure 6. Pictures of different types of emulsions as a function of the transmittance (T) values.

Table 4. Transmittance at wavelength of $600 \mathrm{~nm}(T)$ and hydrodynamic diameters $\left(D_{\mathrm{h}}\right)$ values of DHM-in-water emulsions prepared with 0.2 wt\% of DHM dispersed phase and 10 g. $\mathrm{L}^{-1}(1 \mathrm{wt} \%)$ of PAA-THG on the basis of the water phase.

\begin{tabular}{cccccc}
\hline Emulsion & E1 & E2 & E3 & E4 & E5 \\
\hline Copolymer & PAA90- & PAA180- & PAA294- & PAA345- & PAA180- \\
& THG13 & THG13 & THG13 & THG13 & THG32 \\
$\boldsymbol{T}_{\boldsymbol{\lambda}=\mathbf{6 0 0} \mathbf{n m}(\boldsymbol{\%})}$ & 98.4 & 97.0 & 65.3 & 35.9 & 98.2 \\
$\boldsymbol{D}_{\mathbf{h}}(\mathbf{n m})^{\boldsymbol{a}}$ & 12 & 13 & 725 & 1245 & 12 \\
Observation & Transparent & Transparent & Translucent & Cloudy & Transparent \\
${ }^{\boldsymbol{a}} \boldsymbol{D}_{\mathrm{h}}$ from the volume distribution in DLS. & & &
\end{tabular}


Despite the low variation of DHM/water interfacial tension with $\overline{D P_{n}}$ of PAA of PAAx-THG13 for $\overline{D S} 13 \mathrm{~mol} \%$ (Figure S7 and Figure 5) and the high level of transparency of the copolymer aqueous solutions (Table S1), the increase of $\overline{D P_{n}}$ of PAAx-THG13 stabilizer $(\overline{D S}=13$ mol\%) induced a decrease of the transmittance of the emulsions (E1 to E4, Table 4). The curvature of the nanoemulsion droplets $\left(D_{\mathrm{h}} \sim 13 \mathrm{~nm}\right.$, see Table 4$)$ is higher than the curvature of the large DHM drop used for IFT measurements. One can suggest that the conformation of the PAA-THG copolymer at the oil/water interface of the small droplets is hindered by increasing the PAA molar mass, thus favouring the formation of larger droplets $\left(D_{\mathrm{h}}>700 \mathrm{~nm}\right)$ to decrease the curvature. This enhances the light diffusion ( $35<\mathrm{T}<65 \%$, see Table 4) and induces loss of transparency. Transparent emulsions were obtained with the PAAx-THGy copolymers with the lowest degrees of polymerization ( $x=90$ and 180) whatever the $\overline{D S}$ value (E1, E2 and E5 in Table 4). Thus these HMPAA copolymers were selected as emulsifiers to prepare direct DHM-in-water emulsions with a higher fraction of dispersed DHM phase of $1 \mathrm{wt} \%$ (Table 5) and $2 \mathrm{wt} \%$ (Table S3 in ESI). As reported in Table 5, the weight ratio between the HMPAA stabilizer and the DMH dispersed phase was tuned between 2 to 5 .

Table 5. Transmittance $(T)$ values at $600 \mathrm{~nm}$ of DHM-in-water emulsions (E) prepared with $1 \mathrm{wt} \%$ of DHM dispersed phase on the basis of water and different copolymer ratios.

\begin{tabular}{|c|c|c|c|c|}
\hline Emulsion & Copolymer & $m_{\text {HMPAA }} / m_{\text {DHM }}$ & $\begin{array}{r}\mathbf{T}_{\lambda}=600 \\
\mathrm{~nm}(\%)\end{array}$ & $\begin{array}{l}\text { Visual observation } \\
\text { for emulsion }\end{array}$ \\
\hline E6 & \multirow{4}{*}{ PAA90-THG13 } & 2 & 1.4 & Cloudy \\
\hline E7 & & 3 & 86.5 & Transparent \\
\hline E8 & & 4 & 94.0 & Transparent \\
\hline E9 & & 5 & 94.9 & Transparent \\
\hline E10 & \multirow{4}{*}{ PAA180-THG13 } & 2 & 0.1 & Cloudy \\
\hline E11 & & 3 & 2.6 & Cloudy \\
\hline E12 & & 4 & 30.7 & Cloudy \\
\hline E13 & & 5 & 91.7 & Transparent \\
\hline E14 & \multirow{4}{*}{ PAA180-THG32 } & 2 & 0.5 & Cloudy \\
\hline E15 & & 3 & 91.7 & Transparent \\
\hline E16 & & 4 & 94.6 & Transparent \\
\hline E17 & & 5 & 95.4 & Transparent \\
\hline
\end{tabular}


It can first be noticed that for PAA90-THG13 emulsifier, transparent emulsions (E7 to E9) are obtained for weight ratio of emulsifier versus dispersed phase $\left(m_{\mathrm{HMPAA}} / m_{\mathrm{DHM}}\right)$ equal or above 3 (Table 5) whereas transparency is observed only at a ratio of 5 for PAA180-THG13 emulsifier with higher value of $\overline{D P_{n}}$,PAA and similar $\overline{D S}$ (E13). This effect of $\overline{D P_{n}}$ is in accordance with the conclusions previously drawn from Table 4. At a constant $\overline{D P_{n}}$, PAA of 180, the increase of $\overline{D S}$ in hydrophobic THG (PAA180-THG32) allowed for the preparation of transparent emulsions at lower weight ratio of emulsifier versus dispersed phase $\left(3 \leq m_{\mathrm{HMPAA}} / m_{\mathrm{DHM}} \leq 5\right.$, E15 to E17 in Table 5). The efficient PAA90-THG13 and PAA180-THG13 emulsifiers provided the ability to produce transparent emulsions at higher content of DHM dispersed phase (2 $\mathrm{wt} \%$ based on water phase) for $m_{\mathrm{HMPAA}} / m_{\mathrm{DHM}}$ ratio of 5 (see Table S3 emulsions E18-E19). However, at such higher concentration of emulsifier based on the aqueous phase at $\mathrm{pH} 6\left([\mathrm{PAA}-\mathrm{THG}]=10 \mathrm{wt} \%=100 \mathrm{~g} . \mathrm{L}^{-}\right.$ ${ }^{1}$ ), the more hydrophobic PAA180-THG32 became insoluble and provided cloudy solutions. As intermediate conclusion, the structure of the PAAx-THGy drives the formation of nanoemulsions with the required high level of transparency. The optimised structure of the emulsifier consists in a PAA backbone with a moderate degree of polymerization $\left({\overline{D P_{n}}}_{n}\right.$ PAA $\left.\leq 180\right)$ and an intermediate degree of substitution in hydrophobic THG side chains $(13 \leq \overline{D S} \leq 32)$. It should be noticed that depending on $\overline{D P_{n}}$ value, the increase of the hydrophobic THG content faced issues of emulsifier solubility (see insolubility of PAA90-THG39 and PAA90-THG51 at 10 g. $\mathrm{L}^{-1}(1 \mathrm{wt} \%)$ reported in the second part of this article and insolubility of PAA180-THG32 at 100 g.L $\mathrm{L}^{-1}(10 \mathrm{wt} \%)$ (Table S3)). These results highlight the interest in implementing controlled radical polymerization of acrylic acid in order to finely tune the $\overline{D P_{n}}$ of the PAA precursor of the amphiphilic PAA-THG emulsifiers. All the terpene-in-water emulsions with high level of transparency were characterized by dynamic light scattering (DLS) in order to give an insight in their droplet sizes (see Table S4 in ESI). The hydrodynamic diameters $\left(D_{\mathrm{h}}\right)$ of the main droplets are systemically below $50 \mathrm{~nm}$ so the emulsions can be designated as nanoemulsions. DLS analyses revealed a main population of very small nanodroplets (fast mode of relaxation) with $D_{\mathrm{h}}$ values below $15 \mathrm{~nm}$ and a minor second population of larger droplets (slow mode of relaxation) of $D_{\mathrm{h}}$ ranging between 50 and $180 \mathrm{~nm}$ depending on the PAA-THG emulsifier structure. The calculated fraction in volume of these larger droplets is obviously negligible (see Table S4 in ESI) as the associated scattered light intensity represents only $25 \%$ to $70 \%$ of scattered light depending on their size. Finally, the stability of the transparent nanoemulsions with time was investigated by 
monitoring the transmittance in the wavelength range of 500 to $800 \mathrm{~nm}$ for three months of storage at room temperature. A typical example of the transmittance evolution for the different storage durations is provided in Figure S9 of ESI. The results for emulsion E16 showed that transmittance value decreased slowly with time. The decrease of transmittance is more significant for transmittance measured at lower wavelength $(21 \%, 13 \%$ and $7 \%$ of transmittance loss after 3 months for respectively $\lambda=500 \mathrm{~nm}, 600 \mathrm{~nm}$ and $800 \mathrm{~nm}$ respectively). It is important to note that the selected E16 nanoemulsion remains transparent even after 3 months of storage at room temperature since the transmittance value remained above $70 \%$.

\section{Conclusion}

In summary, a series of amphiphilic copolymers based on acrylic acid (AA) and tetrahydrogeraniol (THG), molecules that can be synthesized from renewable resources, have been conveniently prepared to target different chain lengths of PAA backbone and various degrees of substitution $(\overline{D S})$ in hydrophobic THG side chains. Reversible addition fragmentation transfer (RAFT) polymerization was first implemented to produce a series of PAA of low dispersity and controlled average degree of polymerization $\left(\overline{D P_{n}}=100\right.$ to 300$)$. The efficient esterification of PAA with monohydroxy-THG terpene, confirmed by DOSY NMR, produced amphiphilic copolymers with $\overline{D S}$ ranging between 7 and $45 \mathrm{~mol} \%$. The critical aggregation concentration (CAC) of these amphiphilic copolymers dispersed in aqueous solution at $\mathrm{pH} 6$ was determined by three different methods (viscosimetry, surface tension and dynamic light scattering) which converged towards similar CAC values, from 3.2 to 4.2 g.L.-1 $(0.32$ to $0.42 \mathrm{wt}-\%)$ depending on copolymer structure. The hydrophobically modified PAA proved to be efficient polymeric emulsifiers to stabilize terpene-in-water direct emulsions with dihydromyrcenol (DHM) as dispersed phase. The objective of the present work to prepare transparent nanoemulsions stabilized by a bio-based polymeric emulsifier was achieved by tuning the structure of the PAAx-THGy copolymers. The optimised structure of the emulsifier for emulsion transparency consists in a PAA backbone with a moderate degree of polymerization $\left(\overline{D P}_{n}\right.$, PAA $\left.\leq 180\right)$ and an intermediate degree of substitution in hydrophobic THG side chains $(13 \leq \overline{D S} \leq 32 \mathrm{~mol} \%)$. Fragrance-based aqueous formulations of 
high level of transparency were successfully prepared for varying concentrations of DHM terpene dispersed phase (0.2 to $2 \mathrm{wt}-\%)$ by adjusting the copolymer/DHM weight ratio.

\section{Acknowledgements}

The authors are grateful to Aquitaine Science Transfer for funding PAATER project. Dérivés Résiniques Terpéniques (DRT Company) is acknowledged for kindly supplying THG and DHM terpenes. The Equipex Xyloforest program (ANR-10-EQPX-16 XYLOFOREST) is acknowledged for MALLS detector and NMR probe funding. Dr. A. Khoukh is acknowledged for DOSY NMR analysis and Dr. E. Deniau for support in SLS.

\section{Appendix A. Supplementary material}

\section{References}

[1] I. Danielsson, B. Lindman, The definition of micro-emulsion, Colloids and Surfaces 3(4) (1981) 391-392.

[2] S. Slomkowski, J.V. Aleman, R.G. Gilbert, M. Hess, K. Horie, R.G. Jones, P. Kubisa, I. Meisel, W. Mormann, S. Penczek, R.F.T. Stepto, Terminology of polymers and polymerization processes in dispersed systems (IUPAC Recommendations 2011), Pure and Applied Chemistry 83(12) (2011) 2229-2259.

[3] L. Chiappisi, L. Noirez, M. Gradzielski, A journey through the phase diagram of a pharmaceutically relevant microemulsion system, J. Colloid Interface Sci. 473 (2016) 52-59.

[4] X.B. Yan, P. Alcouffe, G. Sudre, L. David, J. Bernard, F. Ganachaud, Modular construction of single-component polymer nanocapsules through a one-step surfactant-free microemulsion templated synthesis, Chem. Commun. 53(8) (2017) 1401-1404.

[5] T.G. Mason, J.N. Wilking, K. Meleson, C.B. Chang, S.M. Graves, Nanoemulsions: formation, structure, and physical properties, J. Phys.-Condes. Matter 18(41) (2006) R635-R666.

[6] J.M. Gutierrez, C. Gonzalez, A. Maestro, I. Sole, C.M. Pey, J. Nolla, Nano-emulsions: New applications and optimization of their preparation, Curr. Opin. Colloid Interface Sci. 13(4) (2008) 245-251.

[7] D.J. McClements, Nanoemulsions versus microemulsions: terminology, differences, and similarities, Soft Matter 8(6) (2012) 1719-1729.

[8] A. Gupta, H.B. Eral, T.A. Hatton, P.S. Doyle, Nanoemulsions: formation, properties and applications, Soft Matter 12 (2016) 2826-2841.

[9] M.J. Lawrence, G.D. Rees, Microemulsion-based media as novel drug delivery systems, Adv. Drug Deliv. Rev. 45(1) (2000) 89-121.

[10] T.F. Tadros, Colloid Aspects of Cosmetic Formulations with Particular Reference to Polymeric Surfactants, in: T.F. Tadros (Ed.), Colloids in Cosmetics and Personal Care, Volume 4: Colloids and Interface Science, Wiley2011, pp. 1-34.

[11] N. Sharma, M. Bansal, S. Visht, P.K. Sharma, G.T. Kulkarni, Nanoemulsion: A new concept of delivery system, Chron Young Sci 1 (2010) 2-6. 
[12] L.I. Atanase, G. Riess, Block copolymers as polymeric stabilizers in non-aqueous emulsion polymerization, Polym. Int 60 (2011) 1563-1573.

[13] L.I. Osipow, Transparent emulsions, J. Soc. Cosmetic Chem (1963) 277-285.

[14] P. Perrin, F. Lafuma, Low hydrophobically modified poly(acrylic acid) stabilizing macroemulsions: Relationship between copolymer structure and emulsion properties, J. Colloid Interface Sci 197 (1998) 317-326.

[15] M.H. Alves, H. Sfeir, J.F. Tranchant, E. Gombart, G. Sagorin, S. Caillol, L. Billon, M. Save, Terpene and Dextran Renewable Resources for the Synthesis of Amphiphilic Biopolymers, Biomacromolecules 15(1) (2014) 242-251.

[16] X. Meng, P. Tsobanakis, J. Malsam, T. Abraham, Extraction process for separating and recovering 3-hydroxypropionic acid from aqueous mixtures of 3-hydroxypropionic acid and acrylic acid, Cargill, Incorporated, USA . 2005, p. 17 pp.

[17] T. Blaschke, D. Pfeiffer, N.T. Woerz, M. Zajaczkowski-Fischer, M. Hartmann, Method for producing acrylic acid, BASF SE, Germany . 2015, p. 45pp.

[18] J.L. Garces, G.J.M. Koper, M. Borkovec, Ionization equilibria and conformational transitions in polyprotic molecules and polyelectrolytes, J. Phys. Chem. B 110(22) (2006) 10937-10950.

[19] O. Colombani, E. Lejeune, C. Charbonneau, C. Chassenieux, T. Nicolai, Ionization Of Amphiphilic Acidic Block Copolymers, J. Phys. Chem. B 116(25) (2012) 7560-7565.

[20] M. Fujiwara, R.H. Grubbs, J.D. Baldeschwieler, Characterization of pH-dependent poly(acrylic acid) complexation with phospholipid vesicles, J. Colloid. Interface. Sci 185 (1997) 210-216.

[21] J.E. Glass, A perspective on the history of and current research in surfactant-modified watersoluble polymers, J. Coating Technol 73 (2001) 79-98.

[22] J.I. Kroschwitz, Encyclopedia of polymer science and engineering, 2nd ed, in: J.I. Kroschwitz (Ed.), Encyclopedia of polymer science and engineering, 2nd ed, Wiley, New York, 1989, pp. 772-784.

[23] M.A. Winnik, A. Yekta, Associative polymers in aqueous solution, Curr. Opin. Colloid Interface Sci 2 (1997) 424-436.

[24] K.T. Wang, I. Iliopoulos, R. Audebert, Viscometric behaviour of hydrophobically modified poly(sodium acrylate), Polym. Bull 20 (1988) 577-582.

[25] X. Xie, T.E. Hogen-Esch, Copolymers of N,N-Dimethylacrylamide and 2-(Nethylperfluorooctanesulfonamido)ethyl acrylate in aqueous media and in bulk. Synthesis and properties, Macromolecules 29 (1996) 1734-1745.

[26] I. Iliopoulos, Association between hydrophobic polyelectrolytes and surfactants, Curr. Opin. Colloid. Interface Sci. 2 (1998) 493-498.

[27] S. Biggs, J. Selb, F. Candau, Effect of surfactant on the solution properties of hydrophobically modified polyacrylamide, Langmuir, 8 (1992) 838-847.

[28] C. Note, J. Koetz, S. Kosmella, B. Tiersch, Hydrophobically modified polyelectrolytes used as reducing and stabilizing agent for the formation of gold nanoparticles, Colloid Polym. Sci. 283 (2005) 1334-1342.

[29] J. Galindo-Alvarez, K.A. Le, V. Sadtler, P. Marchal, P. Perrin, C. Tribet, E. Marie, A. Durand, Enhanced stability of nanoemulsions using mixtures of non-ionic surfactant and amphiphilic polyelectrolyte, Colloid Surfaces A 389 (2011) 237-245.

[30] P. Perrin, F. Lafuma, R. Audebert, Emulsions stabilized with hydrophobically modified poly(acrylic acid), Prog. Colloid Polym. Sci 105 (1997) 228-238. 
[31] Q. Li, R. Yuan, Y. Li, Study on the molecular behavior of hydrophobically modified poly(acrylic acid) in aqueous solution and its emulsion-stabilizing capacity, J. Appl. Polym. Sci., 128 (2013) 206-215.

[32] R.Y. Lochhead, C.J. Rulison, An investigation of the mechanism by which hydrophobically modified hydrophilic polymers act as primary emulsifiers for oil-in-water emulsions. 1. Poly(acrylic acids) and hydroxyethyl celluloses, Colloid Surfaces A 88 (1994) 27-32.

[33] H. Zhou, G.Q. Song, Y.X. Zhang, J. Chen, M. Jiang, T.E. Hogen-Esch, R. Dieing, L. Ma, L. Haeussling, Hydrophobically modified polyelectrolytes, 4: Synthesis and solution properties of fluorocarbon containing poly(acrylic acid), Macromol. Chem. Phys 202 (2001) 3057-3064.

[34] B. Imre, B. Pukanszky, From natural resources to functional polymeric biomaterials, European Polymer Journal 68 (2015) 481-487.

[35] A. Llevot, A. Hufendiek, Biobased polyesters and polyamides: Quo vadis, European Polymer Journal 85 (2016) 647-648.

[36] S. De Smet, S. Lingier, F.E. Du Prez, MacroRAFT agents from renewable resources and their use as polymeric scaffolds in a grafting from approach, Polym. Chem. 5(9) (2014) 3163-3169.

[37] P.A. Wilbon, F.X. Chu, C.B. Tang, Progress in Renewable Polymers from Natural Terpenes, Terpenoids, and Rosin, Macromolecular Rapid Communications 34(1) (2013) 8-37.

[38] P. Sarkar, A.K. Bhowmick, Synthesis, characterization and properties of a bio-based elastomer: polymyrcene, Rsc Advances 4(106) (2014) 61343-61354.

[39] J. Hilschmann, G. Kali, Bio-based polymyrcene with highly ordered structure via solvent free controlled radical polymerization, European Polymer Journal 73 (2015) 363-373.

[40] M.F. Sainz, J.A. Souto, D. Regentova, M.K.G. Johansson, S.T. Timhagen, D.J. Irvine, P. Buijsen, C.E. Koning, R.A. Stockman, S.M. Howdle, A facile and green route to terpene derived acrylate and methacrylate monomers and simple free radical polymerisation to yield new renewable polymers and coatings, Polym. Chem. 7(16) (2016) 2882-2887.

[41] S.-S. Baek, S.-H. Hwang, Preparation of biomass-based transparent pressure sensitive adhesives for optically clear adhesive and their adhesion performance, European Polymer Journal 92 (2017) 97-104.

[42] A. Kalaitzaki, N.E. Papanikolaou, F. Karamaouna, V. Dourtoglou, A. Xenakis, V. Papadimitriou, Biocompatible colloidal dispersions as potential formulations of natural pyrethrins:a structural and efficacy study, Langmuir, 31 (2015) 5722-5730.

[43] P.H. Li, B.H. Chiang, Process optimization and stability of D-limonene-in-water nanoemulsions prepared by ultrasonic emulsification using response surface methodology, Ultrason. Sonochem 19 (2012) 192-197.

[44] W.C. Lu, B.H. Chiang, D.W. Huang, P.H. Li, Skin permeation of D-limonene-based nanoemulsions as a transdermal carrier prepared by ultrasonic emulsification, Ultrason. Sonochem 21 (2014) 826-832.

[45] W.C. Lu, T.J. Zhang, D.W. Huang, P.H. Li, Nanoemulsion of D-limonene in water system prepared by ultrasonic emulsification, J. Cosmet. Sci 65 (2014) 245-252.

[46] H. Schellekens, W.E. Hennink, V. Brinks, The immunogenicity of polyethylene glycol: Facts and fiction, Pharmaceutical Research 30(7) (2013) 1729-1734.

[47] K.B. Guice, Y.L. Loo, Reversible phase transformations in concentrated aqueous block copolymer solutions of poly(methyl acrylate)-b-poly(hydroxyethyl methacrylate-codimethylaminoethyl methacrylate), Macromolecules 40(25) (2007) 9053-9058.

[48] J. Brandrup, E.H. Immergut, E.A. Grulke, Polymer Handbook, 4th Edition, John Wiley, New York ed.1999. 
[49] E. Lejeune, C. Chassenieux, O. Colombani, pH Induced Desaggregation Of Highly Hydrophilic Amphiphilic Diblock Copolymers, in: V. Starov, K. Prochazka (Eds.), Trends in Colloid and Interface Science Xxiv2011, pp. 7-16.

[50] J. Loiseau, N. Doerr, J.M. Suau, J.B. Egraz, M.F. Llauro, C. Ladaviere, Synthesis and characterization of poly(acrylic acid) produced by RAFT polymerization. Application as a very efficient dispersant of CaCO3, kaolin, and TiO2, Macromolecules 36(9) (2003) 3066-3077. [51] L. Couvreur, C. Lefay, J. Belleney, B. Charleux, O. Guerret, S. Magnet, First nitroxidemediated controlled free-radical polymerization of acrylic acid, Macromolecules 36(22) (2003) 8260-8267.

[52] C. Ladaviere, N. Dorr, J.P. Claverie, Controlled radical polymerization of acrylic acid in protic media, Macromolecules 34(16) (2001) 5370-5372.

[53] H. Hussain, B.H. Tan, C.S. Gudipati, C.B. He, Y. Liu, T.P. Davis, Micelle formation of amphiphilic polystyrene-b-poly(N-vinylpyrrolidone) diblock copolymer in methanol and watermethanol binary mixtures, Langmuir, 19 (2009) 5557-5564.

[54] Ö. Topel, B.A. Cakir, L. Budama, N. Hoda, Determination of critical micelle concentration of polybutadiene-block-poly(ethyleneoxide) diblock copolymer by fluorescence spectroscopy and dynamic light scattering, J. Mol. Liq 177 (2013) 40-43.

[55] J. Hao, Z. Li, H. Cheng, C. Wu, C.C. Han, Kinetically driven intra- and interchain association of hydrophobically and hydrophically modified poly(acrylic acid) in dilute aqueous solutions, Macromolecules 43 (2010) 9534-9540. 